\title{
Quantitative Analysis of Obsidian and Determination of Source Provenance Using an Analytical Dual Beam SEM
}

Edward Vicenzi ${ }^{1}$, Meredith Sharps ${ }^{2}$ and Thomas Lam ${ }^{1}$

${ }^{1}$ Smithsonian Institution, Museum Conservation Institute, Suitland, Maryland, United States, ${ }^{2}$ Rochester Institute of Technology, Image Permanence Institute, United States

Obsidian artifact discoveries cover a wide range of geography and timescales dating from hundreds of years before present $(\mathrm{BP})$ to $\approx 320,000 \mathrm{BP}[1,2]$. The general utility and widespread use of obsidian make it an archaeologically important material that has helped unravel the history and prehistory of humans, including its use to create permanent artistic expression on skin as tattoos [3]. Obsidian is a volcanic rock that contains trace volumes of crystals relative to a glassy matrix, and when fractured, particularly in a controlled manner, results in the formation of a razor sharp edge [4]. Artifacts created from obsidian comprise perhaps the sharpest-edged cutting tools manufactured and compare favorably to $21^{\text {st }}$ century surgical stainless steel scalpel knife edges [5]. This typically black volcanic glass also possesses a useful geochemical trait in that ratios of minor to trace elements can often be linked to its geographical origin [6]. We have demonstrated the use of a new tool to measure these elements through co-located scanning electron microscope (SEM)-based micro-X-ray fluorescence spectrometry (mXRF) and electron beam induced X-ray microanalysis. A rigorous evaluation of this dual microbeam analysis was performed by examining the major, minor, and trace elements within a wellcharacterized rhyolitic glass reference material to provide the measurement science foundation for understanding the method's capabilities and limitations. This coupled X-ray spectrometry method was recently used to identify the source locations for two varieties of highly polished, kilogram-sized Mesoamerican obsidian "mirrors"/tablets from Central Mexico that are housed in the collections of the Smithsonian's National Museum of the American Indian (NMAI) [7], demonstrating the utility of this method for archaeological science.

The principal subject for a comparative analysis of the co-located X-ray and electron beam techniques is Yellowstone rhyolitic glass from Obsidian cliffs, Yellowstone National Park, Wyoming (NMNH 72854/VG568), which has been previously characterized by classical wet chemical methods [8] and served as an internal reference analyzed during the NMAI obsidian tablet study. Reference obsidians from Central Mexico held by the National Museum of Natural History's National Rock and Ore Collection were used to train a statistical procedure termed Canonical Discriminate Analysis and provided a targeted comparison to the NMAI collection materials from two volcanic complexes in the Trans-Mexican Volcanic Belt known to be of archaeological importance in the pre-Colonial and Colonial eras. Analysis was performed using an Hitachi S3700N SEM and a Rh source Bruker XTrace mXRF using an X-ray optic that produces a beam $\approx 33 \mathrm{~mm}$ in diameter (measured at $\mathrm{Cu} \mathrm{K}$ ) [9]. The X-ray signals generated by the electron- and mXRF-beams were collected using a Bruker XFlash 6|60 silicon drift detector. Quantification was performed using standardsbased and fundamental parameters analysis for electron beam and $\mathrm{mXRF}$ analysis respectively within the Esprit v2.1 software platform. Estimates for the information depth were obtained using DTSA II [10] for electron beam microanalysis and XRF Check $[11,12]$ for $\mathrm{mXRF}$.

Combining the results from two microanalysis methods requires an appreciation of analytical differences: 1) spatial resolution, 2) uncertainties, and 3) sensitivity. In terms of depth resolution, $90 \%$ of the emitted X-rays generated by the electron beam come from less than $1.5 \mathrm{~mm}$ of the specimen surface, while the same benchmark used for $\mathrm{mXRF}$ results in a wide range of depths across the upper periodic table (Figure 1). XRF depths are strongly dependent upon the energy of the X-ray line and major element X-rays in obsidian for atomic numbers < K come from the uppermost $5 \mathrm{~mm}$ of the specimen surface. This depth difference of a factor of $\approx 4$ for a material chemically homogenized by high temperatures and mechanical mixing in nature is negligible, and one could rightly argue that the larger volume analyzed by XRF is a more faithful representation of the bulk glass [7]. 
Given differences in the quantification methodology for electron beam and $\mathrm{mXRF}$, the major and minor oxide values are in general agreement between the two measurement techniques (Figure 2), where values for $\mathrm{Al}_{2} \mathrm{O}_{3}$ and $\mathrm{CaO}$ are within $1 \mathrm{~s}$ and $\mathrm{K}_{2} \mathrm{O}$ within $3 \mathrm{~s} . \mathrm{SiO}_{2}$ and $\mathrm{Fe}_{2} \mathrm{O}_{3}{ }^{*}$ are outside of $3 \mathrm{~s}$ of one another (Table 1). Despite the gap in $\mathrm{SiO}_{2}$ values, both techniques straddle the value for the reference glass within $1.5 \%$ of the accepted composition $(76.7 \%)$. Spatial inhomogeneities in microscale Fe oxide minerals formed by flow banding in obsidian likely account for the $\mathrm{Fe}_{2} \mathrm{O}_{3}$ results and can be ascribed to the analytical volume difference between the electron and photon beams [7]. The XRF value for K shows the greatest deviation from the expected value for major oxides at $14.5 \%$, while both methods deviate $18 \%$ below the expected minor $\mathrm{CaO}$ value $(0.5 \%)$. In broad terms, the SEM-based electron beam method is most suitable for elemental concentrations $>1500$ ppm while the mXRF is useful for more dilute species at the 10s of parts per million level.

The SEM-based analytical dual beam method shows significant promise and has important advantages for the analysis of museum objects including: 1) a complete composition ranging from major to trace elements is obtained, 2) fine scale electron beam imaging is used to position the XRF beam for analysis, 3) the technique is nondestructive for specimens that fit into the chamber $(<300 \mathrm{~mm}$ long axis) and can tolerate low vacuum pressures, thereby eliminating the need for the application of a conductive film, and 4) it can serve as a screening tool for more sophisticated analyses performed at large facilities, e.g. X-ray absorption, or finerscale micro-X-ray fluorescence spectrometry at synchrotron light sources.

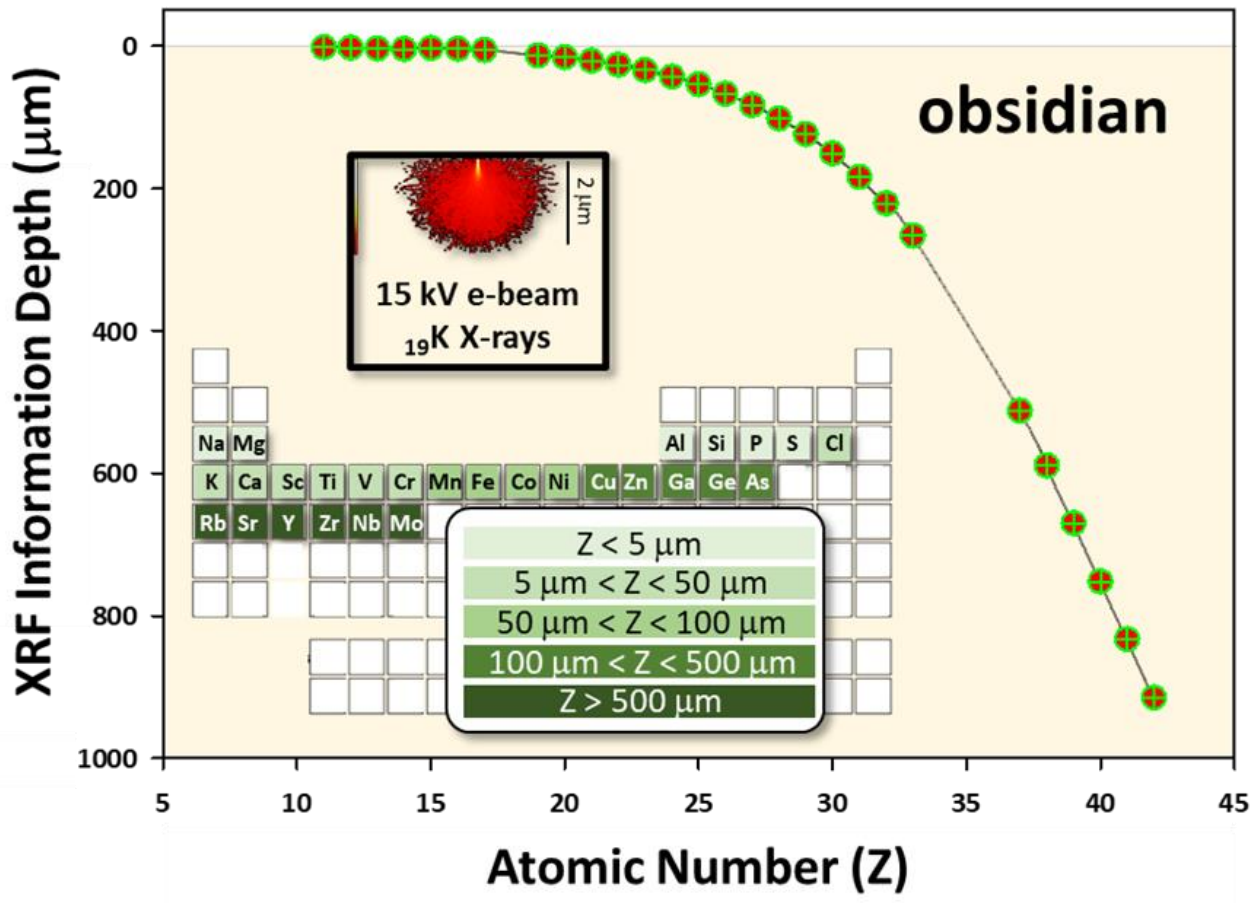

Figure 1. Information depth for XRF signals (see text) in obsidian for twenty-eight elements where the gray curve represents a spline fit to the data, and the periodic table is color coded into five element groups that define depth zones. Inset plot represents the emission image for K K-line $\mathrm{X}$-rays $(\mathrm{Z}=19)$ generated by a $15 \mathrm{kV}$ electron beam. 


\section{Yellowstone Obsidian Cliff Rhyolitic Glass}

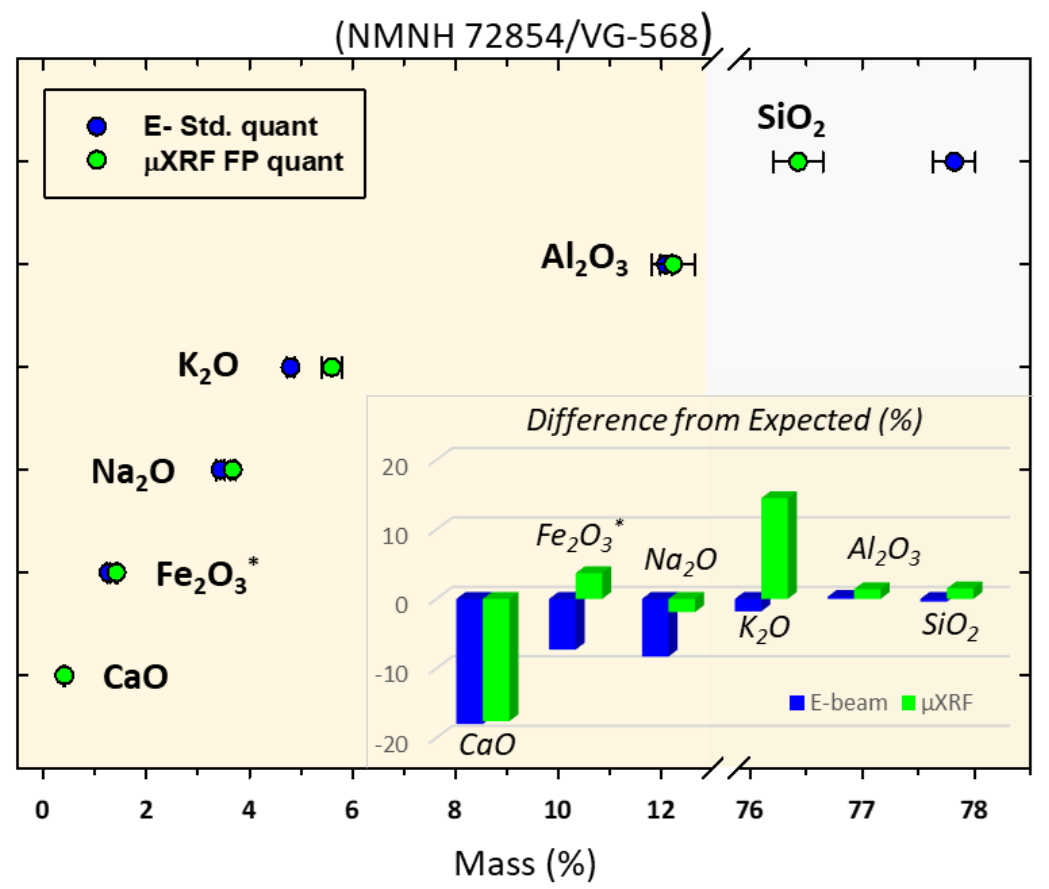

Table 1.

\begin{tabular}{|c|c|c|c|c|c|c|c|c|}
\hline $\begin{array}{c}\text { NMNH } \\
72854 / \text { VG- } \\
568\end{array}$ & $\begin{array}{c}\text { mass } \\
(\%)\end{array}$ & $\begin{array}{c}\text { E-beam } \\
\text { (mean) } \\
n=33\end{array}$ & $\sigma$ & $\begin{array}{c}\text { DFE } \\
\%\end{array}$ & $\begin{array}{c}\text { mass } \\
(\%)\end{array}$ & $\begin{array}{c}\mu \mathrm{XRF} \\
\text { (mean) } \\
n=61\end{array}$ & $\sigma$ & $\begin{array}{c}\text { DFE } \\
\%\end{array}$ \\
\hline 76.71 & $\mathrm{SiO}_{2}$ & $77.82 \pm$ & 0.19 & 1.4 & $\mathrm{SiO}_{2}$ & $76.43 \pm$ & 0.22 & -0.4 \\
\hline 12.06 & $\mathrm{Al}_{2} \mathrm{O}_{3}$ & $12.09 \pm$ & 0.11 & 0.2 & $\mathrm{Al}_{2} \mathrm{O}_{3}$ & $12.23 \pm$ & 0.42 & 1.4 \\
\hline 4.89 & $\mathrm{~K}_{2} \mathrm{O}$ & $4.80 \pm$ & 0.07 & -1.8 & $\mathrm{~K}_{2} \mathrm{O}$ & $5.60 \pm$ & 0.20 & 14.5 \\
\hline 3.75 & $\mathrm{Na}_{2} \mathrm{O}$ & $3.44 \pm$ & 0.08 & -8.3 & $\mathrm{Na}_{2} \mathrm{O}$ & $3.68 \pm$ & 0.05 & -1.9 \\
\hline 1.37 & $\mathrm{Fe}_{2} \mathrm{O}_{3} *$ & $1.27 \pm$ & 0.03 & -7.3 & $\mathrm{Fe}_{2} \mathrm{O}_{3} *$ & $1.42 \pm$ & 0.02 & 3.6 \\
\hline$\underline{0.50}$ & $\mathrm{CaO}$ & $\underline{0.41} \pm$ & 0.02 & -18.0 & $\mathrm{CaO}$ & $\underline{0.412 \pm}$ & 0.004 & -17.6 \\
\hline \multirow[t]{10}{*}{99.28} & total & 99.83 & & & total & 99.77 & & \\
\hline & & & & & $\Sigma$ tr. ox. & 0.21 & & \\
\hline & & & & & $\mathrm{ppm}$ & $\mathrm{n}=19$ & & \\
\hline & & & & & $\mathrm{Ti}$ & $420 \pm$ & 12 & -41.7 \\
\hline & & & & & $\mathrm{Mn}$ & $177 \pm$ & 8 & -23.3 \\
\hline & & & & & $\mathrm{Zn}$ & $165 \pm$ & 10 & \\
\hline & & & & & $\mathrm{Rb}$ & $380 \pm$ & 38 & \\
\hline & & & & & $Y$ & $113 \pm$ & 12 & \\
\hline & & & & & $\mathrm{Zr}$ & $227 \pm$ & 32 & \\
\hline & & & & & $\mathrm{Nb}$ & $54 \pm$ & 8 & \\
\hline
\end{tabular}

Figure 2. Mean composition for the Yellowstone rhyolitic reference glass determined by SEM standards-based EDS (blue-filled circles) and micro-XRF FP analysis (green-filled circles) where error bars represent $1 \mathrm{~s}$ population statistics for major and minor oxides. Inset bar plot depicts the difference from expected values for major and minor oxides relative to accepted values [8]. Table 1. Mean composition of Yellowstone rhyolitic reference glass (NMNH 72854/VG-568) obtained using electron beam and mXRF quantification, where major and minor oxide are expressed as mass percent and trace elements as $\mathrm{mg} / \mathrm{kg}$, or parts per million (ppm) of 
cations. Difference from expected (DFE) is a measure of the accuracy of the values relative to canonical wet chemical values determined by Jarosewich [8] (Note: $\mathrm{Zn}, \mathrm{Rb}, \mathrm{Y}, \mathrm{Zr}$, and $\mathrm{Nb}$ were not reported previously). $\mathrm{Fe}_{2} \mathrm{O}_{3}{ }^{*}$ (total iron) represents the sum of $\mathrm{Fe}^{2+}$ and $\mathrm{Fe}^{3+}$.

\section{References}

1. Brooks, A.S., et al., Long-distance stone transport and pigment use in the earliest Middle Stone Age. Science, 2018. 360(6384): p. 90-94.

2. Jackson, T.L. and J.E. Ericson, Prehistoric exchange systems in California, in Prehistoric exchange systems in North America. 1994, Springer. p. 385-415.

3. Deter-Wolf, A., et al., The world's oldest tattoos. Journal of Archaeological Science: Reports, 2016. 5: p. 19-24.

4. Dibble, H.L. and Z. Rezek, Introducing a new experimental design for controlled studies of flake formation: results for exterior platform angle, platform depth, angle of blow, velocity, and force. Journal of Archaeological Science, 2009. 36(9): p. 1945-1954.

5. Disa, J.J., J. Vossoughi, and N.H. Goldberg, A comparison of obsidian and surgical steel scalpel wound healing in rats. Plastic and reconstructive surgery, 1993. 92(5): p. 884-887.

6. Glascock, M.D., Comparison and contrast between XRF and NAA: used for characterization of obsidian sources in Central Mexico, in X-ray fluorescence spectrometry (XRF) in geoarchaeology. 2011, Springer. p. 161-192.

7. Sharps, M.C., et al., A dual beam SEM-based EDS and micro-XRF method for the analysis of largescale Mesoamerican obsidian tablets. Journal of Archaeological Science: Reports, 2021. 35: p. 102781.

8. Jarosewich, E., J. Nelen, and J.A. Norberg, Reference samples for electron microprobe analysis. Geostandards Newsletter, 1980. 4(1): p. 43-47.

9. Haschke, M. and S. Boehm, Micro-XRF in Scanning Electron Microscopes, in Advances in Imaging and Electron Physics. 2017, Elsevier. p. 1-60.

10. Ritchie, N.W., Spectrum simulation in DTSA-II. Microscopy and Microanalysis, 2009. 15(5): p. 454. 11. Haschke, M., Laboratory micro-X-ray fluorescence spectroscopy. Cham: Springer International Publishing, 2014. 10: p. 978-983.

12. Wolff, T. Information Depth - XRF Check. 2020; Available from: https://xrfcheck. bruker.com/InfoDept 